\title{
Nod2 sensing of lysozyme-digested peptidoglycan promotes macrophage recruitment and clearance of $S$. pneumoniae colonization in mice
}

\author{
Kimberly M. Davis, ${ }^{1}$ Shigeki Nakamura, ${ }^{1,2}$ and Jeffrey N. Weiser ${ }^{1}$ \\ 1Department of Microbiology, University of Pennsylvania School of Medicine, Philadelphia, Pennsylvania, USA. \\ 2Department of Molecular Microbiology and Immunology, Nagasaki University Graduate School of Biomedical Sciences, Nagasaki, Japan.
}

\begin{abstract}
Streptococcus pneumoniae colonizes the mucosal surface of the human upper respiratory tract. A colonization event is gradually cleared through phagocytosis by monocytes/macrophages that are recruited to the airway lumen. Here, we sought to define the bacterial and host factors that promote monocyte/macrophage influx and $S$. pneumoniae clearance using intranasal bacterial challenge in mice. We found that the recruitment of monocytes/macrophages required their expression of the chemokine receptor CCR2 and correlated with expression of the CCR2 ligand CCL2. Production of CCL2 and monocyte/macrophage recruitment were deficient in mice lacking digestion of peptidoglycan by lysozyme (LysM) and cytosolic sensing of the products of digestion by Nod2. Ex vivo macrophages produced CCL2 following bacterial uptake, digestion by LysM, and sensing of peptidoglycan by Nod2. Sensing of digested peptidoglycan by Nod2 also required the pore-forming toxin pneumolysin. The generation of an adaptive immune response, as measured by anti-pneumococcal antibody titers, was also LysM- and Nod2-dependent. Together, our data suggest that bacterial uptake by professional phagocytes is followed by LysM-mediated digestion of S. pneumoniae-derived peptidoglycan, sensing of the resulting products by Nod2, release of the chemokine CCL2, and CCR2-dependent recruitment of the additional monocytes/macrophages required for the clearance of an S. pneumoniae colonization event.
\end{abstract}

\section{Introduction}

For many opportunistic pathogens, colonization of a mucosal surface is the first step in the pathogenesis of infection. Streptococcus pneumoniae (the pneumococcus) serially colonizes the mucosal surface of the human upper respiratory tract, and a single colonization event typically lasts several weeks to months before the organism is cleared $(1,2)$. The maintenance of colonizing organisms in the nasopharynx also provides the reservoir for transmission of the pneumococcus within the population. A murine model of human S. pneumoniae colonization has enabled the study of host factors that contribute to loss of the carrier state $(3,4)$. The gradual clearance of colonization requires a sustained influx of monocytes/macrophages, which recognize and phagocytose bacterial cells in the lumen of the nasal airways (5). Processing of pneumococci by professional phagocytes is also critical for the generation of adaptive immune responses that may attenuate subsequent pneumococcal challenge $(4,6,7)$. The focus of this study is to further define the bacterial and host factors that promote the influx of monocytes/macrophages and clearance.

Inflammatory responses are generally initiated following sensing of microbial products by pattern recognition receptors, including TLRs and nucleotide-binding oligomerization domain-like (Nodlike) receptors (NLRs) (8-11). In particular, TLR2 senses lipidmodified constituents on $S$. pneumoniae $(5,12)$, which contributes to clearance of colonization through the Th17 response and the influx of monocytes/macrophages (5). However, the effects of sens-

Conflict of interest: The authors have declared that no conflict of interest exists. Citation for this article: J Clin Invest. 2011;121(9):3666-3676. doi:10.1172/JCI57761. ing by TLR 2 on bacterial clearance were limited, indicating that additional factors must function in the innate immune response to colonizing pneumococci.

One of the NLRs, Nod2, senses internalized S. pneumoniae in vitro (13); however, it is unclear whether Nod2-mediated signaling contributes to the host response during infection. Nod2, which is expressed most prominently within leukocytes (14), senses bacterial peptidoglycan fragments containing muramyl dipeptide (MDP) $(15,16)$. Sensing of peptidoglycan by Nod2 initiates a signaling cascade that results in NF- $\kappa \mathrm{B}$ activation and the transcription of proinflammatory cytokines and chemokines (14). Because of the cytoplasmic localization of Nod2, it was originally thought that Nod2 was only important in sensing intracellular pathogens that replicate and shed peptidoglycan into the host cytoplasm. However, Nod2 has recently been shown to contribute to the host response to several predominantly extracellular pathogens $(17,18)$. Pneumococcal cell wall components cause inflammation in several animal models of infection and contribute to Nod2-dependent apoptosis in a sepsis-associated neuronal damage model $(12,19-22)$. However, it remains unclear how Nod2 ligands are released from polymerized peptidoglycan, how these ligands access the host cytoplasm to interact with Nod2, and how Nod2 promotes bacterial clearance.

The most abundant peptidoglycan-degrading enzyme on the mucosal surface is lysozyme (23). Lysozyme hydrolyzes the $\beta-1,4$ glycosidic bond between the $\mathrm{C} 1$ carbon of $\mathrm{N}$-acetyl muramic acid (MurNAc) and the C4 carbon of $\mathrm{N}$-acetylglucosamine (GlcNAc) residues of the peptidoglycan backbone. Mice have two isoforms of lysozyme: LysM, which is secreted by the epithelium and expressed within phagosomes of myelomonocytic cells such as macrophages 

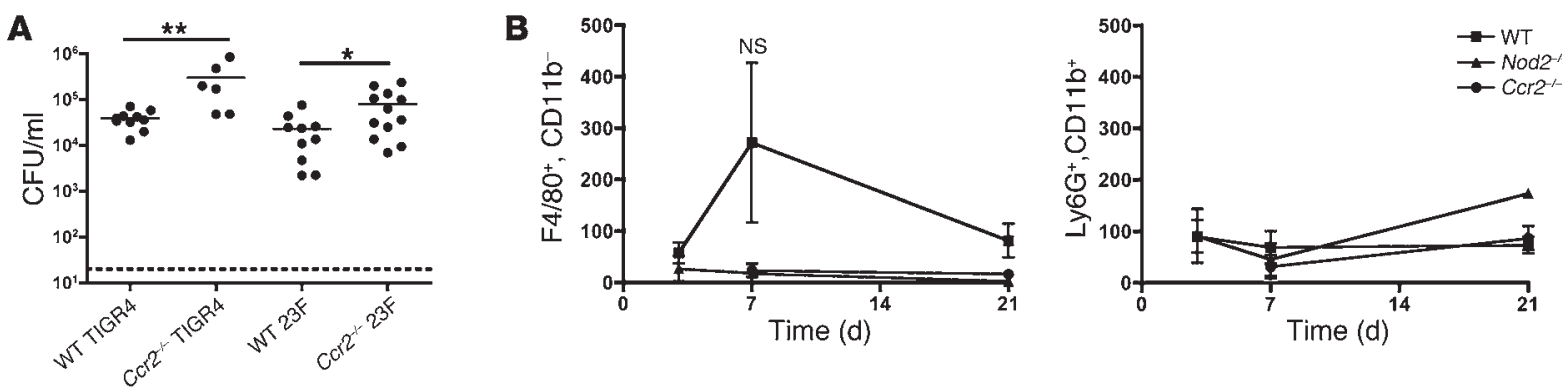

\section{Figure 1}

Monocyte/macrophage recruitment impacts early clearance of $S$. pneumoniae and requires CCR2 and Nod2. Mice of the indicated genetic backgrounds were inoculated intranasally with $10^{7} \mathrm{CFU}$ S. pneumoniae. Upper respiratory tract lavages were used to measure colonization density $(\mathrm{CFU} / \mathrm{ml})$ and the composition of the cellular infiltrate by flow cytometry. (A) Colonization density of WT (C57BL/6) or Ccr2-/- mice at day 7 after inoculation with strain TIGR4 or strain 23F. The dashed line indicates the limit of detection. Horizontal lines indicate mean values. ${ }^{*} P<0.05$, ${ }^{* *} P<0.01$, Mann-Whitney $U$ test. (B) Flow cytometry was used to detect total numbers of monocytes/macrophages (F4/80+, CD11b-) and neutrophils $\left(\mathrm{Ly}_{6 \mathrm{G}}+\mathrm{CD} 11 \mathrm{~b}+\right.$ ) in nasal lavages during colonization of WT (C57BL/6), Nod2 $2^{--}$, or Ccr2 $2^{-/-}$mice with strain $23 \mathrm{~F}$. Each point represents the average number of events $\pm S D$ in 3 experiments each with 5 mice.

and neutrophils $(24,25)$; and LysP, which is expressed by Paneth cells of the small intestine. Because of the abundance of lysozyme on host surfaces, many mucosal pathogens have acquired resistance to lysozyme-mediated degradation by modifying residues of their peptidoglycan backbone (26). S. pneumoniae uses two distinct peptidoglycan modifications to prevent lysozyme digestion; deacetylation of GlcNAc by $\operatorname{PgdA}(27,28)$ and $O$-acetylation of $\mathrm{N}$-acetylmuramic acid by $\mathrm{Adr}$ (29). A mutant strain lacking both of these modifications ( $p g d A^{-} a d r^{-}$) was hypersensitive to hydrolysis by recombinant human lysozyme, and clearance was accelerated (30). However, it was unclear whether this was due to bacterial lysis by LysM or to the sensing of digested peptidoglycan fragments and subsequent inflammatory responses.

Here we show that the innate immune response to colonizing pneumococci is dependent on peptidoglycan release by LysM and sensing by Nod2. Processing and sensing of peptidoglycan within professional phagocytes leads to expression of the CCR2 ligand CCL2, which maintains the recruitment of monocytes/macrophages to the site of infection. Together with sensing by TLR2, these Nod2dependent responses promote the clearance of colonization.

\section{Results}

Monocyte/macrophage recruitment impacts early clearance of S. pneumoniae and requires CCR2 and Nod2. The trafficking of inflammatory monocytes to sites of inflammation requires expression of the chemokine receptor CCR2, which senses the presence of CC-motif chemokines (31). To determine whether CCR2 expression impacts infection by $S$. pneumoniae, we challenged $\mathrm{Ccr} 2^{-/-}$mice intranasally with strain TIGR4 (type 4) or strain 23F (type 23F), and colonization density was compared with that in WT control mice. $\mathrm{Cr} 2^{-/-}$mice had significantly higher levels of each strain at day 7 after inoculation, when monocyte/macrophage recruitment peaks, indicating that CCR2 impacts early clearance of pneumococcal colonization (Figure 1A).

To confirm that CCR2 expression was required for the monocyte/macrophage influx in response to pneumococcal colonization, $\mathrm{Ccr} 2^{-/-}$mice were colonized intranasally with strain $23 \mathrm{~F}$, and the cellular infiltrate in the upper respiratory tract was analyzed by flow cytometry. Ccr2 $2^{-/-}$mice showed diminished monocyte/macrophage $\left(\mathrm{F} 4 / 80^{+}, \mathrm{CD} 11 \mathrm{~b}^{-}\right)$recruitment at day 7 , while levels of neu- trophils $\left(\mathrm{Ly}_{6 \mathrm{G}}, \mathrm{CD} 11 \mathrm{~b}^{+}\right)$were similar in WT and $\mathrm{Ccr} 2^{-/-}$mice (Figure $1 \mathrm{~B})$. These results indicated that the monocyte/macrophage recruitment required for clearance of pneumococcal colonization was CCR2-dependent.

To ascertain whether Nod2-dependent sensing contributes to monocyte/macrophage recruitment during colonization, Nod2-/ mice were also colonized intranasally with strain $23 \mathrm{~F}$. Nod2 contributed to monocyte/macrophage recruitment, but did not affect the influx of neutrophils (Figure 1B). These results suggested a mechanism of clearance that involves CCR2-dependent monocyte/macrophage recruitment and the sensing of bacterial peptidoglycan by Nod2.

Lysozyme releases Nod2 ligands and pneumolysin from S. pneumoniae. Nod2 can sense internalized S. pneumoniae (13); however, it remains unclear how Nod2 ligands may be generated during infection. We hypothesized that a host hydrolytic enzyme, such as lysozyme, may release Nod 2 ligands following digestion of peptidoglycan. To determine whether hydrolysis by lysozyme releases Nod2 ligands, we incubated heat-killed S. pneumoniae with human lysozyme and used them to stimulate transiently transfected HEK293T

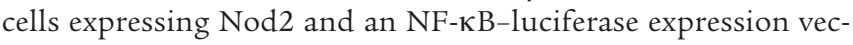
tor. Lipid-based transfection reagents were used to aid in the delivery of bacterial fragments to the cytosol. MDP, the minimal motif sensed by Nod2, was used in these experiments as a positive control. Incubation of the lysozyme-hypersensitive mutant strain TIGR4 $p g d A^{-} a d r$ with lysozyme led to a drop in optical density, indicating bacterial lysis was occurring (Figure 2A). Stimulation of transfected cells with digested TIGR4 $p g d A^{-} a d r$ increased Nod2dependent NF-KB activation compared with undigested bacteria (Figure 2B), indicating lysozyme digestion released Nod2 ligands. Incubation of the parent strain (TIGR4) with lysozyme also significantly increased the release of Nod2 ligands (Figure 2B), but this occurred in the absence of detectable bacterial lysis (Figure 2A). These results indicated that incubation with lysozyme released Nod2 ligands from S. pneumoniae, and this could occur in the absence of bacterial cell lysis.

Since the muramic acid motif sensed by Nod 2 is acetylated by Adr in the parent strain (TIGR4), we determined whether peptidoglycan modifications affect Nod2-dependent sensing. To avoid the effects of modifications on sensitivity to lysozyme, we treated bacteria with 

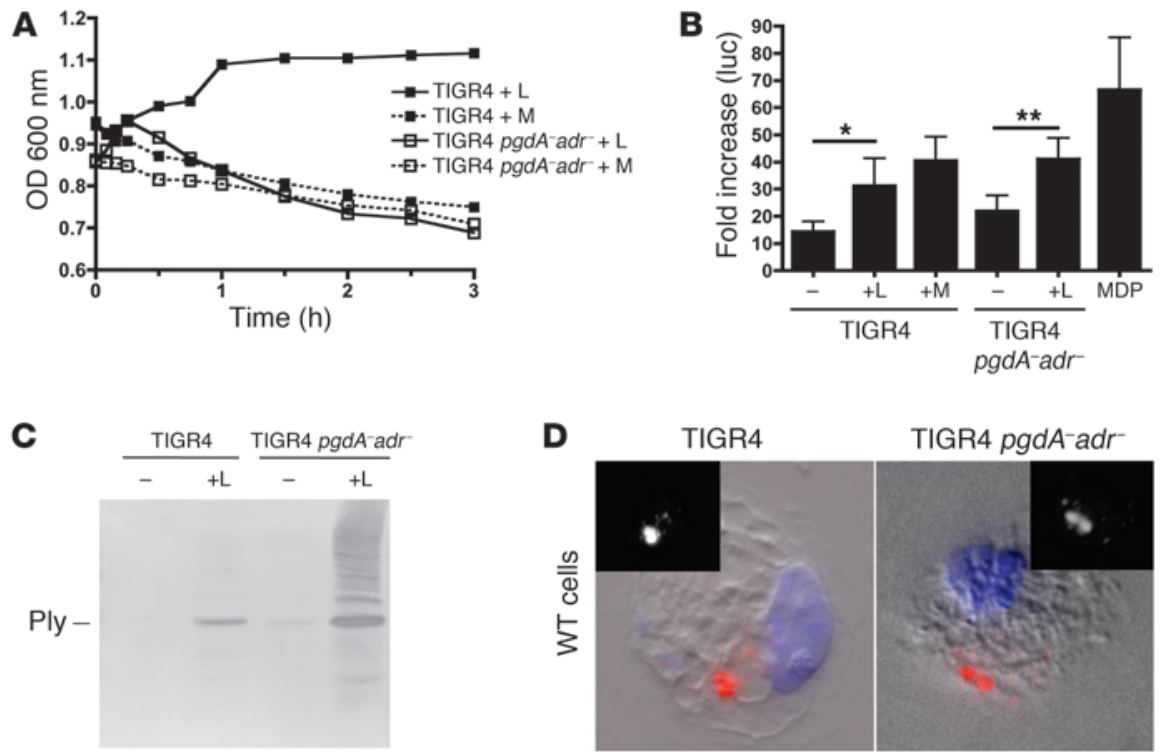

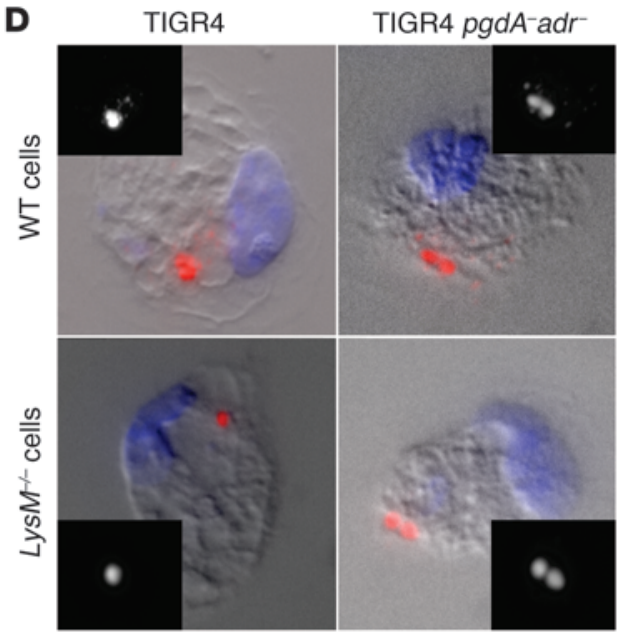

\section{Figure 2}

Lysozyme releases Nod2 ligands and pneumolysin from S. pneumoniae. (A) Lysis of heat-killed bacterial samples with human lysozyme (L) or mutanolysin (M) as measured by optical density (OD at $600 \mathrm{~nm}$ ). (B) HEK293T cells were transiently transfected with an NF-KB-luciferase expression vector and either a Nod2-expressing vector or empty vector control. Transfected cells were stimulated with heat-killed bacteria digested with human lysozyme or mutanolysin or with undigested bacteria (-). Values are expressed as fold increase in relative luciferase units in Nod2-expressing cells compared with empty vector controls $\pm S D$. ${ }^{*} P<0.05$, ${ }^{* *} P<0.01$, Wilcoxon matchedpairs test. (C) Western blot detecting pneumolysin (Ply) released by strain TIGR4 or TIGR4 pgdA-adr following incubation with human lysozyme or no treatment (-). (D) Peritoneal macrophages were isolated from WT (FVB/NJ) or LysM ${ }^{-/-}$mice and infected with strain TIGR4 or TIGR4 pgdA-adr-. Macrophages were stained by immunofluorescence with monoclonal type 4 antisera (red, S. pneumoniae) and DAPI (blue, DNA). Insets show fluorescence images in the red channel. Fluorescence images were overlaid onto Nomarski light images; original magnification, $\times 600$. mutanolysin, a muramidase that hydrolyzes both the parental and mutant strains (Figure 2A). The level of NF- $\mathrm{KB}$ activation stimulated with mutanolysin-digested TIGR4 was similar to that seen with the lysozyme-digested TIGR4 pgdA-adr strain (Figure 2B). These data demonstrated that the peptidoglycan modifications affect sensing primarily through their effect on lysozyme sensitivity.

As an alternative to measuring lysozyme sensitivity by bacterial lysis, pneumococci were incubated with lysozyme, and release of the cell-associated protein pneumolysin was determined by Western blot analysis. Pneumolysin, a pore-forming toxin that is a member of the family of Gram-positive cholesterol-binding cytotoxins, is responsible for much of the inflammatory response to pneumococcal infection $(4,7,32,33)$. Although more pneumolysin was released following incubation of TIGR4 $p g d A^{-} a d r$ with lysozyme, release of pneumolysin was also observed for the TIGR4 parent strain (Figure 2C). Lysozyme-dependent digestion of S. pneumoniae was visualized using immunofluorescence imaging of infected activated peritoneal macrophages. Strains TIGR4 and TIGR4 $p g d A^{-} a d r^{-}$appeared to break down within WT macrophages, while fragments of bacteria were not seen in $L y s M^{-/-}$macrophages (Figure 2D). Together these observations suggested that even with modified peptidoglycan, pneumococci retain enough sensitivity to lysozyme to release sufficient amounts of peptidoglycan for Nod2 sensing. A further implication is that pneumolysin can be released following lysozyme digestion, and that this could occur on mucosal surfaces or within professional phagocytes where LysM is abundant.

S. pneumoniae is digested by LysM within phagocytes, resulting in Nod2dependent sensing and cytokine production. To determine whether phagocytes respond to $S$. pneumoniae in a Nod2-dependent manner, we differentiated macrophages from the bone marrow of
WT and Nod2-/- mice and infected them with strain TIGR4 or TIGR4 $p g d A^{-} a d r$. IL-6 was used as a marker for cytokine production because it is produced following NF- $\kappa \mathrm{B}$ activation and it contributes to the control of pneumococcal infection (34). Bone marrow-derived macrophages produced IL-6 in a Nod2-dependent manner, indicating that Nod 2 within macrophages can sense S. pneumoniae (Figure 3A). The IL-6 response to the TIGR4 and TIGR4 $p g d A^{-} a d r^{-}$strains was similar, suggesting that peptidoglycan modifications do not block the release of Nod2 ligands within macrophages. Heat-killed S. pneumoniae were also sensed in a Nod2-dependent manner (Figure 3B) and were used in further experiments to eliminate the confounding factor of bacterial growth. The actin cytoskeleton inhibitor cytochalasin D, which blocks phagocytosis, eliminated IL- 6 production, indicating that bacterial uptake was required for sensing (Figure 3B). Neither MDP nor purified peptidoglycan (data not shown) was sufficient to stimulate IL-6 production by these cells, which also supported the requirement of bacterial cell uptake. IL- 6 production from activated peritoneal macrophages was also Nod2-dependent (Figure 3C) and LysM-dependent (Figure 3D) in response to parental (TIGR4) and mutant bacterial strains. The IL-6 response to the TIGR4 and TIGR4 pgdA-adr strains was similar, suggesting that within macrophages, peptidoglycan modifications do not block processing by LysM. Together these data confirmed that peptidoglycan modifications do not have a major effect on sensing once peptidoglycan fragments are generated.

Nod2 and LysM are required for the monocyte/macrophage influx in response to pneumococcal colonization. To determine whether the parental TIGR4 and TIGR4 $p g d A^{-} a d r^{-}$strains stimulate similar levels of monocyte/macrophage influx during colonization, WT and 
A

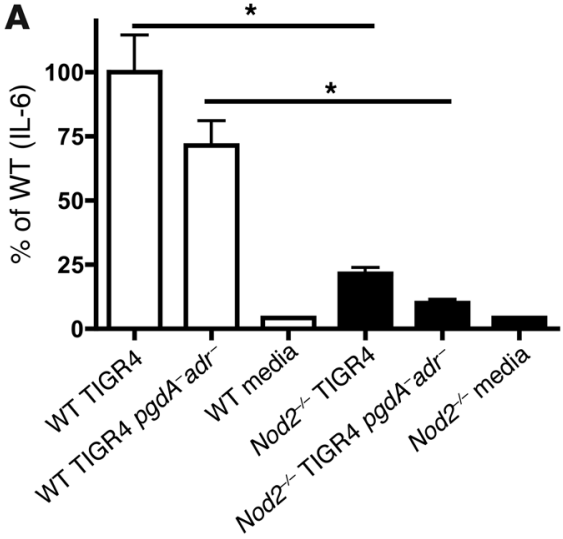

C

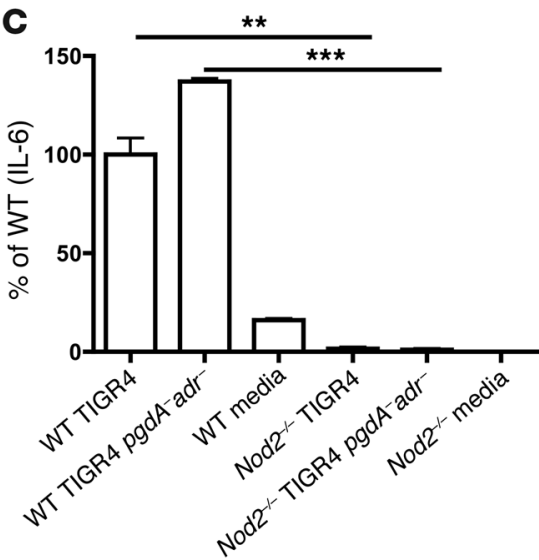

B

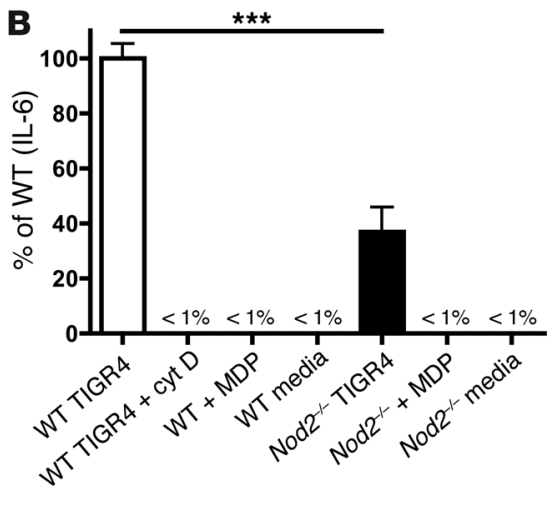

D

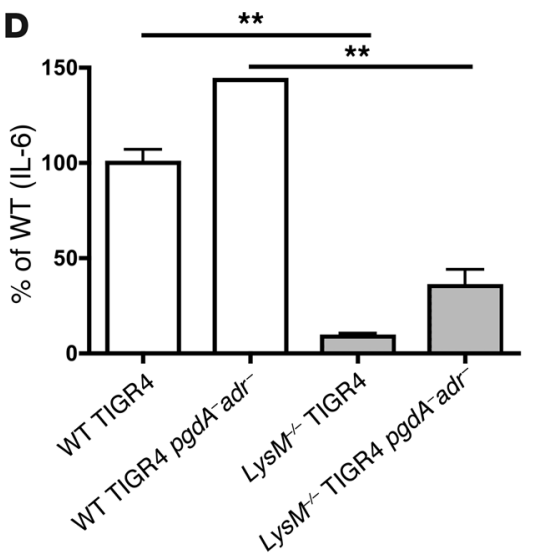

Figure 3

S. pneumoniae is digested by LysM within phagocytes, resulting in Nod2-dependent sensing and cytokine production. (A) WT (C57BL/6, white bars) or $\mathrm{Nod}_{2}^{--}$(black bars) bone marrow macrophages were infected with strain TIGR4, strain TIGR4 pgdA-adr, or media control for 4 hours, and secreted IL- 6 was measured by ELISA. (B) WT (C57BL/6) or Nod2-/- bone marrow macrophages were stimulated with heatkilled strain TIGR4, media control, or MDP for 24 hours, and secreted IL-6 was measured by ELISA. Cytochalasin D (cyt D) was added prior to stimulation to prevent uptake. (C) WT (C57BL/6) or Nod2-/- peritoneal macrophages were stimulated with heat-killed strain TIGR4, heat-killed strain TIGR4 pgdA-adr, or media control, and secreted IL-6 was measured by ELISA. (D) WT (FVB/NJ, white bars) or LysM ${ }^{-1-}$ (gray bars) peritoneal macrophages were stimulated with heat-killed strain TIGR4 or heatkilled strain TIGR4 pgdA-adr, and secreted IL-6 was measured by ELISA. Values are relative to WT cells treated with TIGR $4 \pm \mathrm{SD} .{ }^{*} P<0.05$, ${ }^{\star \star} P<0.01,{ }^{* \star} P<0.001$, unpaired $t$ test.
Nod2 $2^{-/-}$mice were colonized intranasally, and the cellular influx in the upper respiratory tract was analyzed by flow cytometry. Cellular influx was analyzed at day 3 after inoculation, when numbers of pneumococci were similar in WT and immunodeficient mice, to ensure that higher levels of inflammation were not due to the presence of more bacteria. The increase in numbers of monocytes/ macrophages $\left(\mathrm{F} 4 / 80^{+}, \mathrm{CD} 11 \mathrm{~b}^{-}\right)$at this time point required expression of Nod2 and was similar during intranasal infection with the parental TIGR4 or the TIGR4 pgdA $a d r$ strain (Figure 4A). Additionally, the monocyte/macrophage influx in response to the parental TIGR4 strain was also LysM-dependent (Figure 4B), which was consistent with LysM digestion releasing Nod2 ligands. In contrast, numbers of neutrophils $\left(\mathrm{Ly}_{6 \mathrm{G}} \mathrm{G}^{+} \mathrm{CD} 11 \mathrm{~b}^{+}\right)$were similar in WT and immunodeficient mice at this time point.

Expression of CCL2 requires pore formation by pneumolysin. One of the primary chemokines sensed by CCR2 is CCL2 (also know as monocyte chemoattractant protein-1 [MCP-1]), which can be expressed

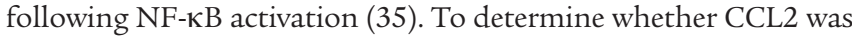
expressed in a Nod2-dependent manner during colonization, we isolated RNA from the upper respiratory tract of WT and $\mathrm{Nod}_{2-1-}$ mice 3 days after inoculation with either strain TIGR4 or strain $23 \mathrm{~F}$. Ccl2 transcript levels correlated with the influx of monocytes/macrophages and were significantly reduced in $\mathrm{Nod}^{-{ }^{--}}$mice (Figure 5A). Ill 7 a transcript levels were also reduced in $\mathrm{Nod}^{-/-}$mice, indicating sensing by Nod 2 may contribute to the Th17 response (Figure $5 \mathrm{~B})$. WT mice were also infected with mutant strains that lacked the pore-forming toxin pneumolysin $\left(p l y^{-}\right)$in either the parental TIGR 4 or $23 \mathrm{~F}$ background. An additional mutant, $23 \mathrm{~F}$ ply $y_{W 433 F}$, which has a point mutation that greatly reduces pore formation $(7,36)$, was also used in these experiments. The expression of $\mathrm{Ccl} 2$ was decreased in the absence of pneumolysin and, furthermore, required its ability to form pores (Figure 5, A and C). To determine whether pore formation also impacts cytokine production from activated phagocytes, peritoneal macrophages were thioglycolateelicited from WT (C57BL/6) mice and stimulated with heat-killed S. pneumoniae. CCL2 production from peritoneal macrophages also required pore formation (Figure $5 \mathrm{D}$ ). Strain $23 \mathrm{~F}$ was used to stimulate macrophages because of the availability of a corrected mutant $\left(p l y^{+}\right)$, which confirmed that CCL2 production correlated with pneumolysin expression (Figure 5D). Pore formation by pneumolysin has previously been shown to allow bacterial peptidoglycan fragments to access the host cytoplasm for sensing by Nod receptors (36).

Nod2-dependent sensing occurs within macrophages, which initiates the immune response to pneumococcal colonization. Nod2-dependent CCL2 expression correlated with the recruitment of monocytes/ macrophages and initiation of the inflammatory response during colonization; however, it was unclear which cells were providing the Nod2-dependent signal. Because Nod2 expression is primarily restricted to myelomonocytic cells $(14,37)$, we focused on the contribution of macrophages and neutrophils. Activated macrophages produced CCL2 in response to S. pneumoniae (Figure 5D), but it was unclear whether this was Nod2-dependent. To confirm that macrophages produce CCL2 in a Nod2-dependent manner in response to strain TIGR4, we differentiated bone marrow-derived macrophages from WT and Nod2-/- mice, stimulated them with heat-killed WT bacteria, and measured levels of secreted CCL2 by 

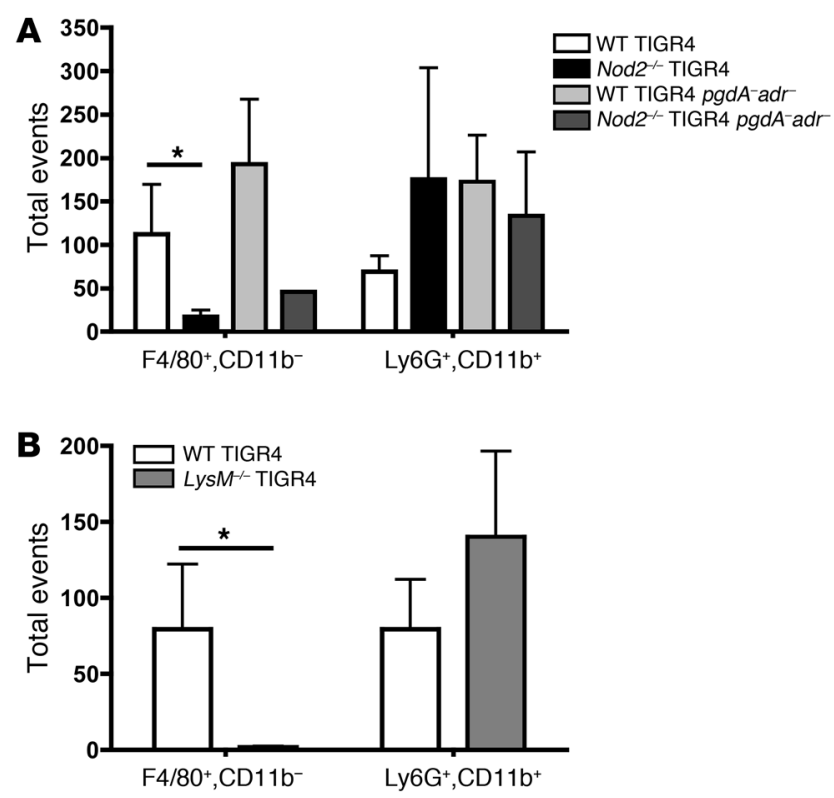

ELISA. Macrophages produced CCL2 in response to S. pneumoniae, and this was Nod2-dependent (Figure 6A).

To determine whether neutrophils also express CCL2 in a Nod2dependent manner, neutrophils and macrophages were caseinelicited from the peritoneum of WT or immunodeficient mice and stimulated with heat-killed bacteria. Bacteria were pre-opsonized

\section{Figure 4}

Nod2 and LysM are required for the monocyte/macrophage influx in response to pneumococcal colonization. Mice of the indicated genetic backgrounds were inoculated intranasally with $10^{7} \mathrm{CFU}$ of $S$. pneumoniae. Upper respiratory tract lavages were obtained 3 days after inoculation, and the composition of the cellular infiltrate was determined by flow cytometry. Numbers of monocytes/macrophages (F4/80+, CD11 b-) and neutrophils $\left(\mathrm{Ly} 6 \mathrm{G}^{+}, \mathrm{CD} 11 \mathrm{~b}^{+}\right)$are shown. (A) WT (C57BL/6) or Nod2 $2^{--}$mice were inoculated with strain TIGR4 or TIGR4 pgdA-adr. (B) WT (FVB/NJ) or $\mathrm{LysM}^{-/-}$mice were inoculated with strain TIGR4. Each bar represents the average the number of events \pm SD in 4 experiments, each with 5 mice. ${ }^{\star} P<0.05$, Mann-Whitney $U$ test.

with serum, which allows both neutrophils and macrophages to take up bacteria. As in bone marrow macrophages, CCL2 production by peritoneal exudate cells was Nod2- and LysM-dependent (Figure $6, \mathrm{~B}$ and C). CCL2 production was inhibited by cytochalasin D treatment, confirming the requirement for phagocytosis in this assay. CCL2 production was also NF- $\mathrm{KB}-$ dependent, which was confirmed using an NF-кB inhibitor (data not shown). To determine which cells in the peritoneal exudates were producing CCL2 in response to pneumococci, we stained cells for surface markers and intracellular CCL2 following bacterial stimulation and then analyzed them by flow cytometry. F4/80+ WT cells stained positive for intracellular CCL2, while F4/80 $0^{+} \mathrm{Nod}^{-1-}$ cells were CCL2negative (Figure 6D). However, all Ly6G ${ }^{+}$cells were CCL2-negative, indicating that Nod2-dependent CCL2 expression was occurring in the $\mathrm{F} 4 / 80^{+}$macrophage population (Figure 6D). Together these data suggested that macrophages contribute to Nod2- and LysM-

\section{Figure 5}

Expression of CCL2 requires pore formation by pneumolysin and sensing by Nod2. (A) Upper respiratory tract lavages were obtained 3 days after inoculation with the indicated strain, using RNA lysis buffer. RNA was isolated and reverse transcribed, and CCL2 expression levels were measured by quantitative RT-PCR relative to GAPDH controls. (B) IL-17A expression levels were measured by quantitative PCR relative to GAPDH controls. (C) CCL2 expression levels were measured by quantitative PCR relative to GAPDH controls. Values are relative to WT (C57BL/6) mice infected with the parental strain \pm SD $(n>10$ mice). Baseline values reflect mice mock-infected with PBS. ${ }^{*} P<0.05$, ${ }^{* *} P<0.01$, unpaired $t$ test. (D) WT (C57BL/6) peritoneal macrophages were stimulated with heat-killed preparations of the indicated strains, and secreted CCL2 was measured by ELISA. ${ }^{*} P<0.05$, unpaired $t$ test.
A
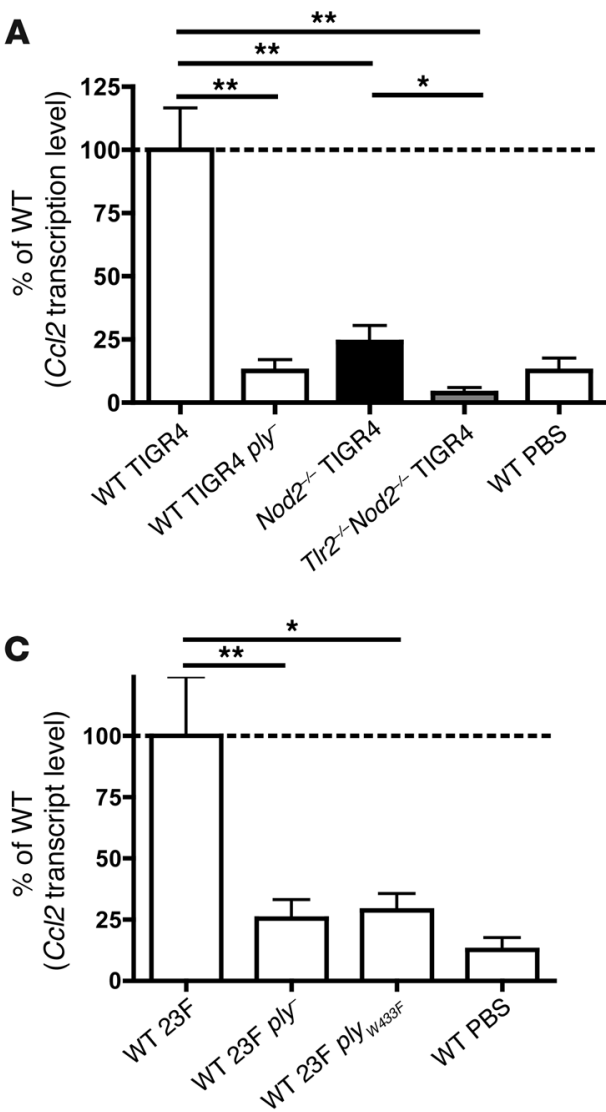

B
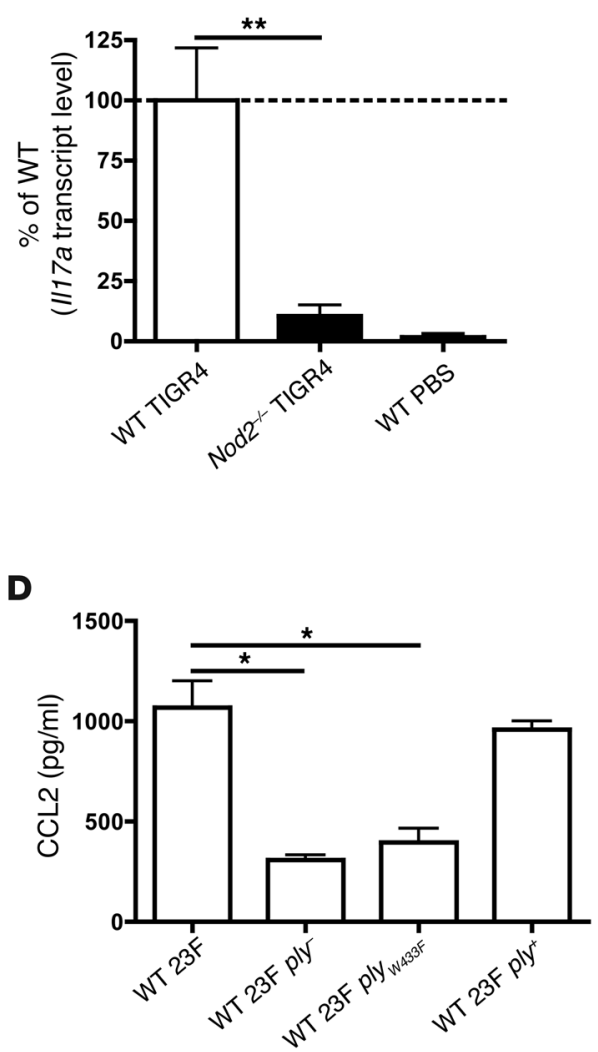
A
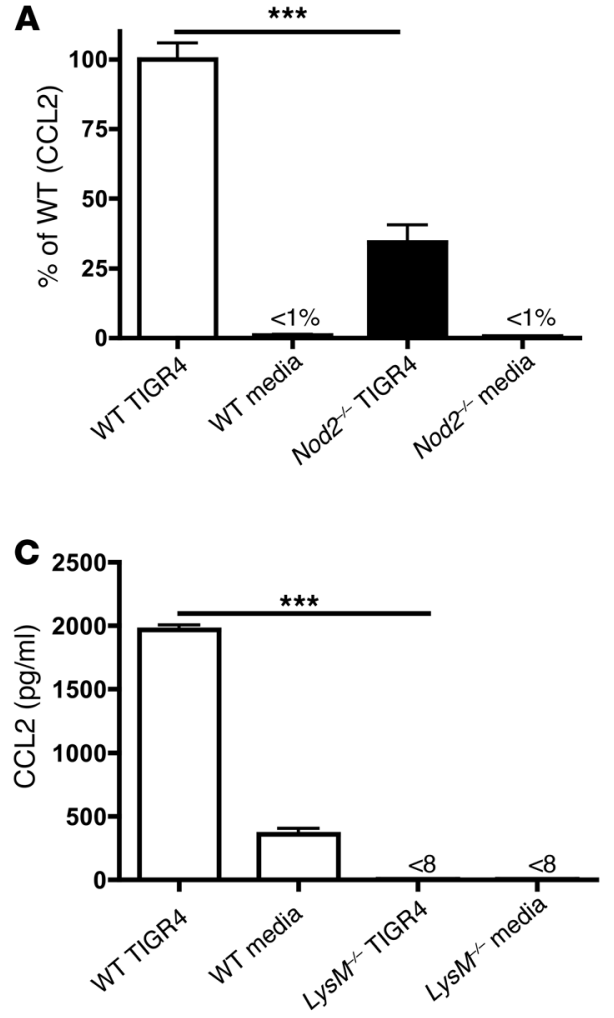

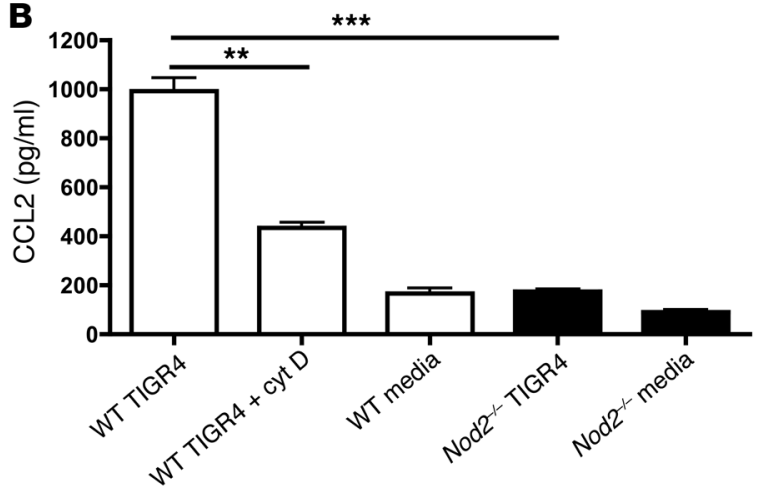

D
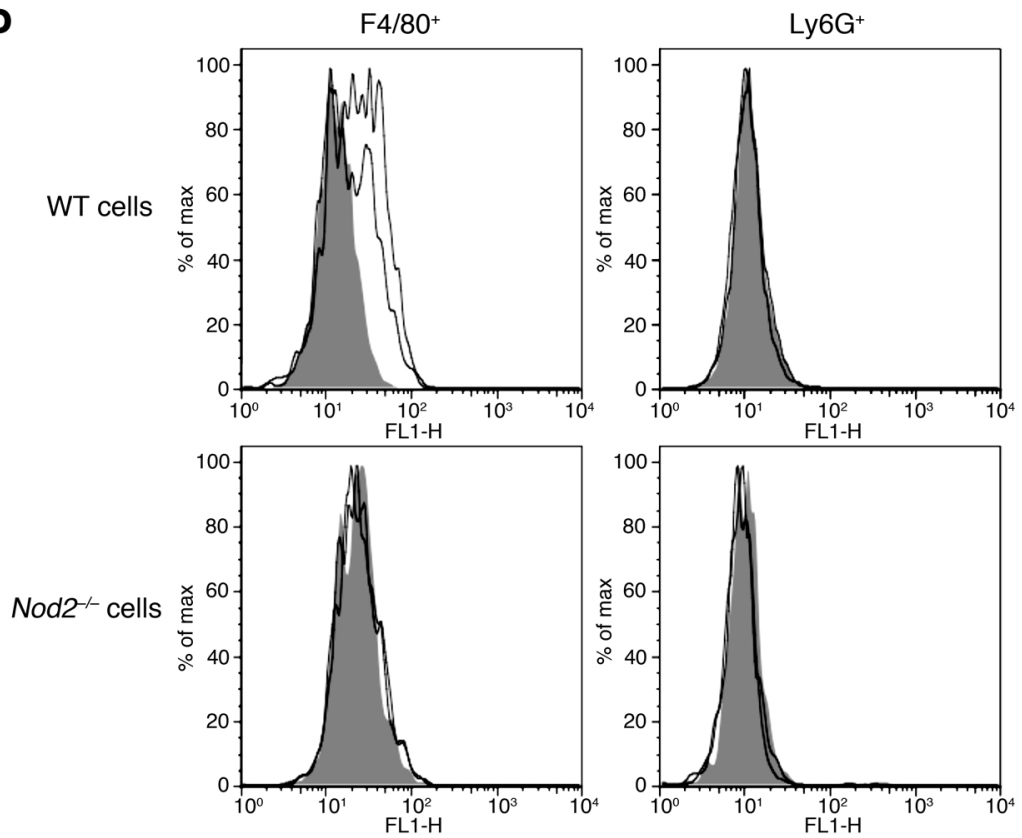

Figure 6

Nod2-dependent sensing occurs within macrophages, which initiates the immune response to pneumococcal colonization. (A) Bone marrow macrophages from WT (C57BL/6, white bars) or Nod2 ${ }^{-1-}$ (black bars) mice were stimulated with heat-killed strain TIGR4, and levels of secreted CCL2 were measured by ELISA. Values are relative to WT mice stimulated with strain TIGR4 \pm SD. (B) Peritoneal cells were isolated from WT (C57BL/6) or Nod2-/- mice and stimulated with opsonized heat-killed TIGR4, and secreted CCL2 was measured by ELISA. Cytochalasin D was added prior to stimulation to prevent uptake. (C) Peritoneal cells were isolated from WT (FVB/NJ) or LysM-l- mice and stimulated with opsonized heat-killed strain TIGR4, and secreted CCL2 was measured by ELISA. ${ }^{* \star} P<0.01,{ }^{* \star *} P<0.001$, unpaired $t$ test. (D) Intracellular CCL2 was detected by flow cytometry following stimulation of peritoneal cells isolated from WT (C57BL/6) or Nod2 ${ }^{-/-}$mice and stimulated with opsonized heat-killed strain TIGR4. Macrophage $\left(\mathrm{F} 4 / 80^{+}\right)$and neutrophil $\left(\mathrm{Ly}_{6 \mathrm{G}}\right)$ populations are shown. Lines indicate $\mathrm{CCL} 2$ fluorescence intensity on the $x$ axis (FL-1 signal) for duplicate cell samples. Filled peaks denote binding by CCL2 isotype control antibodies.

dependent CCL2 expression, which is critical for the recruitment of additional monocytes/macrophages into the upper respiratory tract during colonization.

Nod2 and LysM promote the generation of adaptive immune responses. Several studies have indicated that innate sensing by pattern recognition receptors affects the generation of adaptive immune responses (38-44). To determine whether Nod2- and LysM-dependent responses also affect adaptive immunity, we extended colonization experiments in $\mathrm{Nod}^{-2^{--}}, \mathrm{Lys} \mathrm{M}^{-/-}$, and congenic control mice to day 21 after inoculation, a time point when most WT mice have typically cleared colonization. Serum was analyzed for total antipneumococcal IgG titers by ELISA. Nod2 ${ }^{-/}$mice had significantly lower titers of anti-pneumococcal serum IgG against both strain TIGR4 and strain 23F (Figure 7, A and B). Mice lacking the pattern recognition receptor TLR2 had antibody titers similar to those of WT mice, indicating antibody production was specifically linked to Nod2 signaling (Figure 7A). Levels of anti-pneumococcal serum IgG were also significantly lower in $L y s M^{-/-}$compared with WT mice, indicating that antibody production was also LysM-dependent (Figure 7C). These results demonstrated that the innate responses initiated by Nod 2 and LysM during pneumococcal colonization also impact downstream adaptive immune responses.

Nod2 and TLR2 contribute to clearance of pneumococcal colonization. The pattern recognition receptor TLR2 has also been shown to 

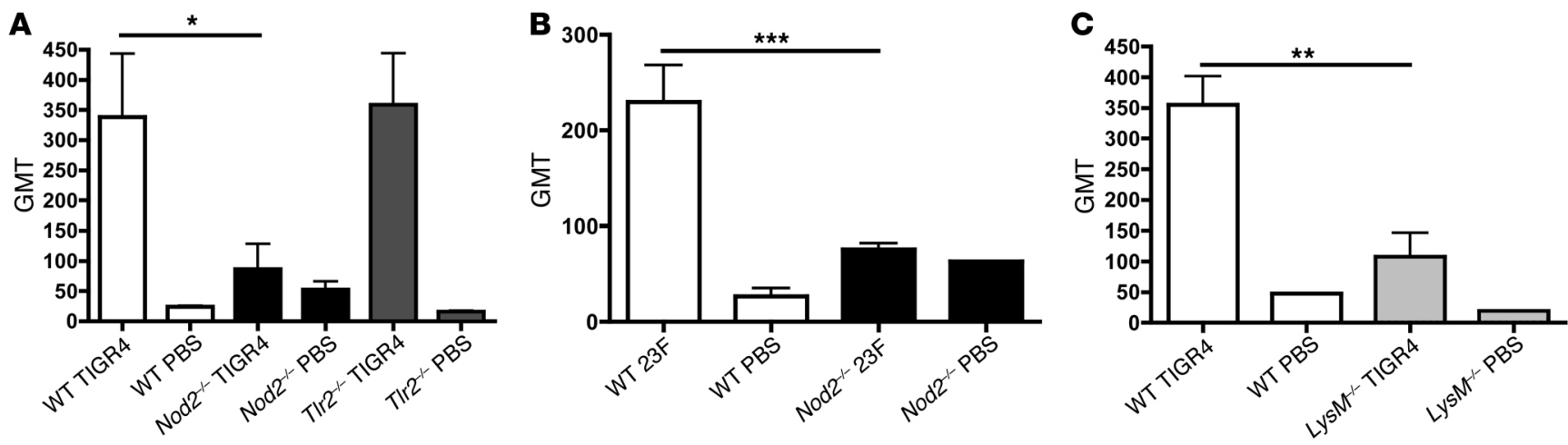

Figure 7

Nod2 and LysM promote the generation of adaptive immune responses. Mice were inoculated intranasally with $10^{7} \mathrm{CFU}$ of the indicated strain or PBS. Twenty-one days after inoculation, mice were sacrificed, serum was isolated, and levels of anti-pneumococcal serum IgG were determined by ELISA. Values are expressed as geometric mean titers (GMT) \pm SD $\left(n>10\right.$ mice). (A) WT (C57BL/6, white bars), Nod2 ${ }^{-1-}$ (black bars), or TIr2 $^{-/-}$(dark gray bars) mice were inoculated with strain TIGR4. (B) WT (C57BL/6) or Nod2 ${ }^{-1-}$ mice were inoculated with strain 23F. (C) WT (FVB/ $\mathrm{NJ}$, white bars) or $\mathrm{LysM}^{-/-}$(light gray bars) mice were inoculated with strain TIGR4. ${ }^{\star} P<0.05,{ }^{\star \star} P<0.01,{ }^{\star \star \star} P<0.001$, Mann-Whitney $U$ test.

contribute to the immune response to pneumococcal colonization, although clearance could occur in the absence of this receptor (5). To determine whether Nod2 and TLR2 play redundant roles in the sensing of $S$. pneumoniae, we generated mice that lack both of these host receptors ( $\mathrm{Tl} \mathrm{2}^{-/-} \mathrm{Nod2^{-/- }}$ ). CCL2 transcript levels were measured in the upper respiratory tract of $\mathrm{Tlr} 2^{-/-} \mathrm{Nod2^{-/- }}$ mice during colonization and were significantly lower than in $\mathrm{Nod2}^{-/-}$ mice, indicating both receptors contributed to CCL2 expression

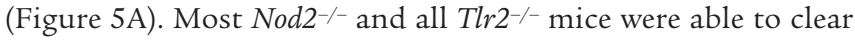
colonization; however, $\mathrm{Tl} \mathrm{2}^{-/-} \mathrm{Nod} 2^{-/-}$mice remained colonized at significantly higher levels at day 21 after inoculation (Figure 8). This observation confirmed the importance of Nod2 in the clearance of colonization, but indicated that TLR2 and Nod2 have redundant roles, since elimination of an individual receptor was not associated with a measurable defect in clearance.

\section{Discussion}

It is well established that Nod receptors sense peptidoglycan fragments and transmit inflammatory signals. There is, in addition, evidence that Nod sensing enhances in vivo host defense (17, $39,43,45-48)$. However, our understanding of the mechanisms responsible for Nod-mediated host defense in vivo is lacking and has not been assessed in the respiratory tract.

Here, we show that following bacterial uptake by professional phagocytes and degradation by LysM, there is Nod2-dependent sensing of pneumococcal peptidoglycan. This stimulates production of the chemokine CCL2, which initiates the recruitment of monocytes/ macrophages to the site of infection. Because monocytes/macrophages are critical to pneumococcal clearance (5), these observations link this pattern recognition receptor to a specific mechanism for host defense. Since the generation of CCL2 by monocytes/macrophages leads to the recruitment of additional monocytes/macrophages necessary to remove bacteria, our model suggests that mononuclear cells both transmit Nod2-dependent signals and are key effectors of the host response. The clearance of colonization occurs over an extended period, and this regulatory circuit may be necessary to sustain the presence of these cells until they eventually eliminate the infection. We also demonstrate how Nod2- and LysM-dependent innate responses contribute to adaptive immunity.
Several aspects of this study merit further comment. Our study focused specifically on professional phagocytes since these cells express the two components needed for the response described here, Nod 2 and LysM. Following bacterial uptake, macrophages increased production of CCL2 in a Nod2-dependent manner. In contrast, we were unable to detect CCL2 production in neutrophils $(49,50)$, the other professional phagocyte recruited in response to pneumococcal colonization. Lysozyme is also abundant within the lumen of the upper airway, raising the possibility that the epithelium could provide a source of LysM that could be important in Nod2-dependent sensing. However, it is unclear whether the respiratory epithelium directly senses peptidoglycan fragments in a Nod2-dependent manner. Cultured cells of the respiratory epithelium do not express detectable levels of Nod2, even after stimulation with LPS or TNF- $\alpha$, which has been shown to upregulate expression of Nod2 in some tissue culture lines (37).

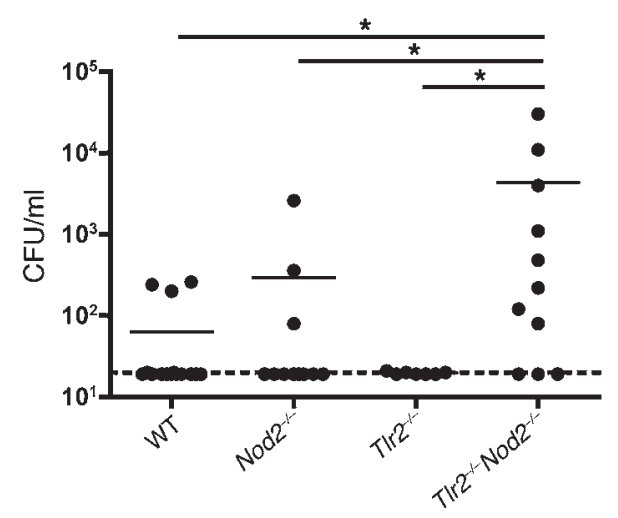

\section{Figure 8}

Nod2 and TLR2 contribute to clearance of pneumococcal colonization. WT (C57BL/6), Nod2-/-, Tlr2-/-, and TIr2---Nod2-/- double-knockout mice were inoculated intranasally with $10^{7} \mathrm{CFU}$ of strain TIGR4. Upper respiratory tract lavages were obtained at 21 days after inoculation and used to measure colonization density (CFU/ml). Dashed lines indicate the limit of detection. Horizontal lines indicate mean values. ${ }^{*} P<0.05$, Mann-Whitney $U$ test. 
We and others have been unable to demonstrate significant levels of Nod2 expression in respiratory epithelial cells in culture, including primary human cells (ref. 14 and data not shown). In contrast, it has been suggested that epithelial cells lining the intestinal tract, and other constituents of the gut epithelium, express Nod 2 and contribute to Nod2-dependent responses $(37,39)$.

The requirement for the pore-forming toxin pneumolysin in Nod2-dependent expression of CCL2 offers a potential mechanism for phagocytosed organisms that do not enter the cytoplasmic compartment to be sensed by Nod2. Pneumolysin could aid in the delivery of peptidoglycan for cytosolic sensing, which is consistent with our results indicating that pore-formation is required for cytokine expression. These results could also explain the delayed clearance of a ply- strain, which may exhibit less Nod2-dependent immunostimulation compared with the parental S. pneumoniae strain (4). Insertion of various pore-forming toxins into host membranes has been shown to facilitate the delivery of other microbial products for cytoplasmic surveillance $(46,51)$. However, pneumolysin is cell associated and lacks a secretion signal or dedicated secretion apparatus for transiting to the extracellular compartment $(52,53)$. Bacterial degradation within the phagosome could allow for release of the toxin from phagocytosed pneumococci. In this regard, we demonstrated that treatment of pneumococci with lysozyme was sufficient to trigger release of the toxin. It will be important to determine whether similar events occur during infection. Pneumolysin has been shown to facilitate Nod 1 sensing through the transit of peptidoglycan fragments released into the milieu of epithelial cells in culture (54). The requirement for bacterial uptake by phagocytic cells suggests that pneumolysin could act on the phagosomal rather than cytoplasmic membrane to aid in Nod2-dependent responses, although further experiments are needed to confirm this hypothesis.

An additional question was how cell wall fragments sensed by Nod 2 are generated from macromolecular assemblies of crosslinked peptidoglycan. S. pneumoniae can spontaneously lyse during growth due to activity of the autolysin LytA; however, LytA cleaves MurNAc from the stem peptide and breaks down Nod2 ligands (55). Studies with bacteria lacking peptidoglycan modifications, which are lysozyme-sensitive (through mutation in $p g d A$ ), have shown that lysozyme digestion can lead to the release of Nod ligands (56). In our study, the requirement for lysozyme in the response to parental $S$. pneumoniae strains was not predicted, since pneumococci resist its lytic effects. Although peptidoglycan modifications prevented detectable cell lysis, we showed that incubation with lysozyme was sufficient for release of Nod2 ligands. The degree of lysozyme sensitivity may be a determining factor in the characteristic inflammatory response to different pathogens and may vary depending on the proportion of modified residues in each organism (57). S. aureus $O$-acetyltransferase (oat A, an ortholog of pneumococcal $a d r$ ) confers resistance to lysozyme and suppresses inflammasome activation following phagocytosis (58). However, the sensing of $S$. aureus ligands released by lysozyme was Nod2-independent. For S. pneumoniae, the effect of Adr alone on lysozyme resistance is minimal, which may be due to a lower proportion of modified residues. It is unclear why the pneumococcus would retain some sensitivity to lysozyme, although it has been shown that peptidoglycan modifications have a fitness cost to the bacterium (30). Alternatively, the activity of LysM may be more efficient within the phagosome, where conditions are different and other degradative substances are present. Of note, lysozyme treatment of sensitive mutants before phagocytosis eliminated Nod2 sensing, providing further evidence that LysM acts within the host cell (data not shown).

Among mucosal pathogens, many adaptations to lysozyme involve modification to muramic acid residues. Because this motif encompasses the minimal structure sensed by Nod2, these modifications have the potential to affect sensing by this receptor (59). In the case of mycobacterium, N-glycolylation of muramic acid increases Nod2-stimulating activity (60). However, in the case of the pneumococcus, O-acetylation of muramic acid does not appear to have a major effect on sensing once peptidoglycan fragments are generated.

Clearance of colonization requires a sustained monocyte/macrophage influx into the upper respiratory tract, and these infiltrating cells represent a distinct population that has markers of both inflammatory monocytes and tissue macrophages. Recruited cells express F4/80 (5), typically a marker of a mature subset of tissue macrophages. However, these cells are also CD11b-, which differs from the inflammatory monocytes that are generally recruited to sites of infection via CCR2, and more closely resemble alveolar macrophages, which are also CD11b- (61-63). Alveolar macrophages also express CD11c, which can stain dendritic cell populations and was not found on the surface of the monocyte/macrophage population we studied (63). In addition, Ly6C has been used as a marker of inflammatory monocyte populations (64), and expression of this marker was only seen on the surface of a small subset of cells in the upper respiratory tract. Because of the phenotypic differences in this monocyte/macrophage population, we believe that this population may describe a novel subset of cells that are distinct from inflammatory and resident cells of the lower respiratory tract. Because monocytes/macrophages are never present in large numbers in the upper airway lumen, our in vitro experiments had to rely on the use of both bone marrow and peritoneal macrophages.

Additional cell types are also known to contribute to clearance of pneumococcal colonization. Th17 $\mathrm{CD}^{+}$cells play a key role in clearance $(4,5)$, and transcription of IL-17A was Nod2-dependent, which may indicate Nod 2 signaling occurs upstream of Th17 differentiation. Th17 cells differentiate from naive $\mathrm{CD} 4^{+}$cells in the presence of TGF- $\beta$, IL- 6 , and IL-21 (65). IL- 6 was produced by S. pneumoniae-stimulated macrophages in a Nod2- and LysMdependent manner, which could stimulate the differentiation of these cells during infection. Th17 cells express IL-17, which can activate epithelial cells and lead to the production of additional proinflammatory cytokines and chemokines that aid in the recruitment of neutrophils and macrophages to the site of infection.

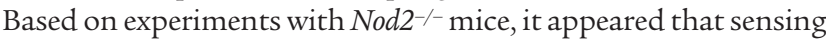
by Nod2 alone was not sufficient to clear pneumococcal colonization. A similar effect was previously shown for a second pattern recognition receptor, TLR2 (5). To show an unambiguous effect of Nod2 in promoting clearance, it was necessary to remove the contribution of TLR2. This finding was also consistent with results showing both receptors contribute to the sensing of pneumococcal cell walls (12). The requirement for both Nod2 and TLR2 demonstrated that these signaling cascades are complementary and together account for much of the hosts' ability to clear colonization. The redundancy of these two signaling pathways may also explain why patients with Nod2 mutations who have intact TLR2 signaling cascades are not more susceptible to pneumococcal infections. However, it also remains possible that other host receptors sense $S$. pneumoniae. Activation of the inflammasome 
complex, which leads to production of IL-1 $\beta$, has been described during pneumococcal infection, which indicates that additional NLRs may contribute to the host response $(66,67)$.

In summary, the generation of peptidoglycan fragments by lysozyme and the sensing of peptidoglycan by Nod 2 orchestrate the production of chemokines that recruit mononuclear cells to clear colonizing pneumococci from the mucosal surface. Our findings provide a paradigm for how Nod 2 promotes mucosal defense in the airway.

\section{Methods}

Bacterial strains and growth conditions. TIGR4, a type 4 clinical isolate and genome-sequenced strain, and the TIGR4 $p g d A^{-} a d r^{-}$strain have been described previously $(30,68)$. The TIGR4 ply- strain was created by transformation with chromosomal DNA from D39 ply- with selection for erythromycin resistance $(1 \mu \mathrm{g} / \mathrm{ml})$, followed by serial back-transformation (30, 32 ). The type $23 \mathrm{~F}$ isolate was previously described in a study of experimental human carriage (2). The $23 \mathrm{~F} p l y^{-}$and $23 \mathrm{~F} p l y_{\mathrm{W} 433 \mathrm{~F}}$ strains have also been previously described $(7,36)$. The $23 \mathrm{~F}$ ply ${ }^{+}$revertant strain was generated by transformation with $23 \mathrm{~F}$ chromosomal DNA, followed by selection for both a loss of antibiotic resistance and the recovery of hemolytic activity. Insertion of the WT ply gene was confirmed by sequencing. Pneumococci were grown as previously described (30).

Murine model of pneumococcal colonization. C57BL/6, Nod2-/- (C57BL/6), Ccr $2^{--}$(C57BL/6), and FVB/NJ mice were obtained from The Jackson Laboratory. $L y s M^{-/-}$mice were generated in the $\mathrm{FVB} / \mathrm{NJ}$ background as previously described $(30,69,70)$ and were provided by H.T. Akinbi (Cincinnati Children's Medical Center, Cincinnati, Ohio, USA). All animal studies were approved by the Institutional Animal Care and Use Committee of the University of Pennsylvania. All strains were animal passaged prior to use in experiments and stored at $-80^{\circ} \mathrm{C}$ in $20 \%$ glycerol. Inocula consisted of $10^{7}$ mid-log-phase PBS-washed bacteria in $10 \mu \mathrm{l}$ PBS and was plated to confirm the dose. At the indicated time points, mice were sacrificed and the trachea cannulated, and $200 \mu \mathrm{l}$ PBS was instilled. Lavage fluid was collected from the nares and serially diluted in PBS. The lower limit of detection was $20 \mathrm{CFU} / \mathrm{ml}$ lavage fluid.

Flow cytometry and intracellular cytokine staining. The nasal lavages of 5 mice from each group were pooled, centrifuged at $250 \mathrm{~g}$, and resuspended in $1 \%$ BSA in PBS. Nonspecific binding was blocked using a rat anti-mouse antibody directed against the FcyIII/II receptor (CD16/CD32) (BD), and the following rat anti-mouse cell surface antibodies were applied: Ly6G (BD), CD11b (BD), and F4/80 (eBioscience). For intracellular staining, peritoneal cells were stimulated and cytokine secretion was blocked using GolgiPlug (BD). Stimulated peritoneal cells were detached from plates by chilling on ice at $4{ }^{\circ} \mathrm{C}$ and washing with ice-cold PBS. Cells were pelleted, resuspended in $1 \% \mathrm{BSA}$, and stained for surface markers. Cells were then fixed and permeabilized using the BD Cytofix/Cytoperm Plus Kit (BD) according to manufacturer's protocol. Accumulation of intracellular CCL2 was detected using an Armenian hamster anti-mouse/human/rat CCL2 (MCP-1) antibody (eBioscience), and the Armenian hamster IgG isotype control was used to detect nonspecific binding.

Digestion of peptidoglycan and heat-killed bacteria. Cell walls were purified and digested as previously described $(30,71)$. Bacteria were grown to late $\log$ phase, resuspended in equal-volume PBS, and heat-killed by incubation at $65^{\circ} \mathrm{C}$ for 30 minutes. Samples contained approximately $10^{9} \mathrm{CFU} /$ $\mathrm{ml}$ and were plated to ensure no viable bacterial cells remained. Hydrolysis of heat-killed bacterial samples was measured by a decline in absorbance (OD $600 \mathrm{~nm}$ ) over 18 hours incubation at room temperature, in the presence of either recombinant human lysozyme $(100 \mu \mathrm{g} / \mathrm{ml})$ (Ventria Bioscience) or mutanolysin $(100 \mu \mathrm{g} / \mathrm{ml})$ (Sigma-Aldrich). Reactions were incubated in cuvettes (Eppendorf), and OD $600 \mathrm{~nm}$ was measured using a BioPhotometer (Eppendorf).
Luciferase assay for detection of Nod2 ligands. HEK293T cells were cultured in DMEM plus $10 \% \mathrm{FCS}$, penicillin $(100 \mathrm{U} / \mathrm{ml})$, and streptomycin $(100 \mu \mathrm{g} /$ $\mathrm{ml}$ ) in a humidified atmosphere of $5 \% \mathrm{CO}_{2}$, at $37^{\circ} \mathrm{C}$. Cells were seeded at a density of $6 \times 10^{4}$ cells/well and transiently transfected using FuGENE 6 Transfection Reagent (Roche) according to the manufacturer's protocol. Transfection reactions contained $25 \mathrm{ng}$ pNF-кB-luciferase (Stratagene), $25 \mathrm{ng}$ pcDNA3-lacZ (Stratagene), and either $50 \mathrm{ng}$ pCMV-Tag-Nod2 (72) or 50 ng empty vector control plasmid (pCMV-Tag2C) (Stratagene). After 4 hours, fresh medium was added to cells with either heat-killed bacteria ( $10^{7}$ cells) or MDP (98.5 ng) (73). Cells were stimulated for 20 hours, and luciferase expression was measured using the Luciferase Assay System (Promega) according to the manufacturer's protocol. Luciferase data were then normalized to $\beta$-gal expression (Miller units) as a measure of transfection efficiency. $\beta$-gal was measured using a Miller assay as previously described (74). Data were expressed as fold difference in relative luciferase units relative to the empty vector control.

Western blot analysis. Bacterial cells were concentrated to $10^{8} \mathrm{CFU} / \mathrm{ml}$, heatkilled, and incubated with human lysozyme as described above. Cells were pelleted and boiled at $100^{\circ} \mathrm{C}$ for 10 minutes, and proteins were separated by SDS-PAGE on a $10 \%$ Tris-HCl gel (Bio-Rad). Proteins were transferred to a polyvinylidene difluoride transfer membrane (Thermo Scientific). Pneumolysin was detected using a monoclonal antibody to pneumolysin (Novocastra) and anti-mouse IgG alkaline phosphatase-conjugated secondary antibody generated in goat (Sigma-Aldrich). Secondary binding was detected using 4-nitro blue tetrazolium and chloride-5-bromo-4-chloro-3-indolylphosphate (Roche).

Isolation and culture of bone marrow-derived cells. Femurs and tibias were isolated from mice of the indicated genetic backgrounds. Bones were washed with $70 \%$ ethanol and then Hank's buffer (without calcium or magnesium). Bone marrow was isolated by flushing bones with macrophage differentiation media: DMEM, 20\% FCS, 30\% L cell-conditioned media, $100 \mathrm{U} / \mathrm{ml}$ penicillin, and $100 \mu \mathrm{g} / \mathrm{ml}$ streptomycin. Bone marrow cells were cultured 7 days in differentiation media at $37^{\circ} \mathrm{C}, 5 \% \mathrm{CO}_{2}$ in a humidified atmosphere. Cells were collected by chilling cultures on ice and washing with ice-cold PBS, then seeded at a density of $5 \times 10^{5}$ cells $/ \mathrm{ml}$ and incubated overnight prior to stimulation. Macrophage differentiation was confirmed by flow cytometry. Macrophages were infected with live bacteria for 4 hours at an MOI of 10 or stimulated 24 hours with $10^{7}$ heat-killed bacteria, and ELISA kits were used to measure levels of IL-6 (eBioscience) and CCL2 (MCP-1, BD) in culture supernatants according to manufacturers' protocols. Where indicated, cytochalasin $\mathrm{D}$ was added 30 minutes prior to stimulation to a final concentration of $5 \mu \mathrm{M}$. No cytotoxicity was observed following stimulation or cytochalasin D treatment, as measured using the Cytotoxicity Detection Kit (LDH) (Roche) according to the manufacturer's protocol.

Isolation and culture of peritoneal cells. Activated macrophages $\left(\mathrm{F} 4 / 80^{+}\right.$, $\mathrm{CD}_{11} \mathrm{~b}^{+}$) were isolated from the peritoneum 3 days after injection with 1.5 $\mathrm{ml} 4 \%$ thioglycolate solution. Cells were harvested in Hank's buffer without $\mathrm{Ca}^{2+}$ or $\mathrm{Mg}^{2+}$ (Invitrogen) with $0.1 \%$ gelatin. Cell populations were separated by Ficoll density gradient centrifugation using Mono-Poly resolving medium according to manufacturer's protocol (MP Biomedicals). Cells were counted using trypan blue staining, seeded at a density of $5 \times 10^{5}$ cells $/ \mathrm{ml}$, and incubated overnight in a humidified atmosphere of $5 \% \mathrm{CO}_{2}$, at $37^{\circ} \mathrm{C}$. Cells were then stimulated 24 hours with $10^{7}$ heat-killed bacteria, and ELISA kits were used to measure levels of IL- 6 (eBioscience) and CCL2 (MCP-1, BD Biosciences) in culture supernatants according to manufacturers' protocols. Where indicated, cytochalasin $\mathrm{D}$ was added 30 minutes prior to stimulation at a concentration of $5 \mu \mathrm{M}$. A mixture of macrophages and neutrophils, as measured by flow cytometry, was isolated following two intraperitoneal injections of $1 \mathrm{ml}$ PBS with $10 \%$ casein 24 hours and 2 hours before harvesting cells. Cells were harvested and seeded as 
described for peritoneal macrophages. For these experiments, heat-killed bacteria were pre-opsonized prior to stimulation with fresh WT murine serum $(66 \%)$, by incubation at $37^{\circ} \mathrm{C}, 30$ minutes with rotation.

Immunofluorescence staining. Peritoneal macrophages were seeded onto poly-L-lysine-coated coverslips (BD) in 24-well plates at a density of $5 \times 10^{5}$ cells $/ \mathrm{ml}$, and incubated overnight in a humidified atmosphere of $5 \% \mathrm{CO}_{2}$, at $37^{\circ} \mathrm{C}$. Macrophages were infected with S. pneumoniae at an MOI of 10 for 2 hours, and cells were washed with PBS and fixed in 2\% PFA for 30 minutes at $37^{\circ} \mathrm{C}$. Cells were permeabilized in PBT (PBS, $0.1 \%$ bovine serum albumin, $0.2 \%$ Triton $\mathrm{X}-100$ ) for 2 minutes at room temperature, and nonspecific binding was blocked with protein blocking reagent (Coulter/Immunotech) for 10 minutes at $37^{\circ} \mathrm{C}$. Bacteria were detected using monoclonal type 4 antisera (provided by M. Nahm, University of Alabama at Birmingham, Birmingham, Alabama, USA) diluted 1:200 in PBT and incubated overnight at $4^{\circ} \mathrm{C}$. Primary antibody binding was detected with a Cy3-conjugated goat anti-mouse IgG1 secondary antibody (Jackson ImmunoResearch Laboratories Inc.) diluted 1:1,000 in PBT and incubated at $37^{\circ} \mathrm{C}$ for 1 hour. Cells were washed in PBS, then $\mathrm{H}_{2} \mathrm{O}$, counterstained with DAPI (Molecular Probes, Invitrogen), and mounted using Cytoseal. Imaging was performed on a Nikon E600 Eclipse microscope equipped with a liquid crystal (Micro-Color RGB-MS-C, CRI) and a high-resolution charge-coupled device (CCD) digital camera (CoolSnap CF, Roper Scientific) with Nomarski optics.

Quantitative RT-PCR. RNA was isolated from the upper respiratory tract following a lavage with $600 \mu \mathrm{l}$ RNA lysis buffer using an RNeasy Mini Kit (QIAGEN) according to manufacturer's protocol. Complementary DNA was reverse transcribed using a high-capacity reverse transcription kit (Applied Biosystems). Approximately $25 \mathrm{ng}$ cDNA was used as a template in reactions with $0.5 \mu \mathrm{M}$ of forward and reverse primers and SYBR Green (Applied Biosystems), according to the manufacturer's protocol. Reactions were carried out using the StepOnePlus Real-Time PCR system, and quantitative comparisons were obtained using the $\Delta \Delta \mathrm{C}_{\mathrm{T}}$ method (Applied Biosystems). The following primers were used in reactions: GAPDH-F: 5'-TGTGTCCGTCGTGGATCTGA-3'; GAPDH-R: 5'-CCTGCTTCACCACCTTCTTGAT-3'; CCL2-F: 5'-AGCTCTCTCTTCCTCCACCAC-3'; CCL2-R: 5'-CGTTAACTGCATCTGGCTGA-3'; IL-17A-F: 5'-TCTCATC-
CAGCAAGAGATCC-3'; and IL-17A-R: 5'-AGTTTGGGACCCCTTTACAC-3'. The average value for WT $(\mathrm{C} 57 \mathrm{BL} / 6)$ mice infected with WT bacteria was set to $100 \%$. Baseline values reflect mice mock-infected with PBS.

Detection of anti-pneumococcal serum IgG. Whole cell bacteria from the colonizing strain was grown to mid-log phase, pelleted, and resuspended to OD $620 \mathrm{~nm}=0.1$ in coating buffer $\left(0.015 \mathrm{M} \mathrm{Na}_{2} \mathrm{CO}_{3}, 0.035 \mathrm{M} \mathrm{NaHCO}_{3}\right)$. Cells were fixed by overnight incubation at $4{ }^{\circ} \mathrm{C}$ on Immulon $2 \mathrm{HB}$ 96-well plates (Thermo). Plates were blocked using 1\% BSA (Sigma-Aldrich) in PBS and washed between steps with PBS containing Brij 35 (0.05\%). Serum samples were added to plates in 2-fold serial dilutions and incubated at room temperature for 2 hours. Pneumococcus-specific antibodies were detected following a 1.5-hour incubation with goat anti-mouse IgG alkaline phosphatase-conjugated antibody. Plates were developed with $p$-nitrophenyl phosphatase (Sigma-Aldrich) and incubated at $37^{\circ} \mathrm{C}$ for a standardized period of 2 hours. The absorbance was read at $415 \mathrm{~nm}$, and geometric mean titers were calculated based on the sample dilution at which $A=0.1$.

Statistics. Statistical comparisons were computed using the Mann-Whitney $U$ test (non-parametric, 2-tailed $t$ test), the Wilcoxon matched-pairs test (non-parametric, paired, 2-tailed $t$ test), or the unpaired $t$ test (2-tailed $t$ test) as denoted in figure legends (Prism 4, GraphPad Software). A P value of less than 0.05 was considered significant.

\section{Acknowledgments}

This work was supported by grants from the U.S. Public Health Service (AI44231 and AI38446). Technical support was also provided by the Morphology Core of the Center for the Molecular Studies of Liver and Digestive Disease (P30 DK50306).

Received for publication February 25, 2011, and accepted in revised form June 22, 2011.

Address correspondence to: Jeffrey N. Weiser, University of Pennsylvania School of Medicine, 402A Johnson Pavilion, 3610 Hamilton Walk, Philadelphia, Pennsylvania 19104-6076, USA. Phone: 215.573.3511; Fax: 215.573.4856; E-mail address: weiser@ mail.med.upenn.edu.
1. Austrian R. Some aspects of the pneumococcal carrier state. J Antimicrob Chemother. 1986; 18(suppl A):35-45.

2. McCool T, Cate T, Moy G, Weiser J. The immune response to pneumococcal proteins during experimental human carriage. $J$ Exp Med. 2002; 195(3):359-365.

3. McCool T, Weiser J. Limited role of antibody in clearance of Streptococcus pneumoniae in a murine model of colonization. Infect Immun. 2004; 72(10):5807-5813

4. van Rossum A, Lysenko E, Weiser J. Host and bacterial factors contributing to the clearance of colonization by Streptococcus pneumoniae in a murine model. Infect Immun. 2005;73(11):7718-7726.

5. Zhang Z, Clarke T, Weiser J. Cellular effectors mediating Th17-dependent clearance of pneumococcal colonization in mice. J Clin Invest. 2009; 119(7):1899-1909.

6. Malley R, Trzcinski K, Srivastava A, Thompson C, Anderson P, Lipsitch M. CD4+ T cells mediate antibody-independent acquired immunity to pneumococcal colonization. Proc Natl Acad Sci U S A. 2005;102(13):4848-4853.

7. Matthias K, Roche A, Standish A, Shchepetov M, Weiser J. Neutrophil-toxin interactions promote antigen delivery and mucosal clearance of Streptococcus pneumoniae. JImmunol. 2008;180(9):6246-6254.

8. Kawai T, Akira S. The role of pattern-recognition receptors in innate immunity: update on Toll-like receptors. Nat Immunol. 2010;11(5):373-384.

9. Janeway CA Jr, Medzhitov R. Innate immune recognition. Annu Rev Immunol. 2002;20:197-216.

10. Fritz J, Ferrero R, Philpott D, Girardin S. Nod-like proteins in immunity, inflammation and disease. Nat Immunol. 2006;7(12):1250-1257.

11. Franchi L, et al. Intracellular NOD-like receptors in innate immunity, infection and disease. Cell Microbiol. 2008;10(1):1-8

12. Moreira L, et al. The TLR2-MyD88-NOD2-RIPK2 signalling axis regulates a balanced pro-inflammatory cytokine response to Gram-positive cell walls. Cell Microbiol. 2008;10(10):2067-2077.

13. Opitz B, et al. Nucleotide binding oligomerization domain proteins are innate immune receptors for internalized Streptococcus pneumoniae. J Biol Chem. 2004;279(35):36426-36432.

14. Ogura Y, Inohara N, Benito A, Chen F, Yamaoka S, Núñez G. Nod2, a Nod1/Apaf family member that is restricted to monocytes and activates NF- $\kappa \mathrm{B}$. J Biol Chem. 2001;276(7):4812-4818.

15. Inohara $\mathrm{N}$, et al. Host recognition of bacterial muramyl dipeptide mediated through Nod2: implications for Crohn's disease. J Biol Chem. 2003; 278(8):5509-5512.

16. Girardin S, et al. Nod2 is a general sensor of peptidoglycan through muramyl dipeptide (MDP) detection. J Biol Chem. 2003;278(11):8869-8872.

17. Deshmukh H, Hamburger J, Ahn S, McCafferty D, Yang S, Fowler VJ. Critical role of Nod2 in regulat- ing the immune response to Staphylococcus aureus. Infect Immun. 2009;77(4):1376-1382.

18. Hsu L, et al. A NOD2-NALP1 complex mediates caspase-1-dependent IL-1b secretion in response to Bacillus anthracis infection and muramyl dipeptide. Proc Natl Acad Sci U S A. 2008;105(22):7803-7808.

19. Majcherczyk P, Langen H, Heumann D, Fountoulakis M, Glauser M, Moreillon P. Digestion of Streptococcus pneumoniae cell walls with its major peptidoglycan hydrolase releases branched stem peptides carrying proinflammatory activity. J Biol Chem. 1999;274(18):12537-12543.

20. Ripley-Petzoldt M, Giebink G, Juhn S, Aeppli D, Tomasz A, Tuomanen E. The contribution of pneumococcal cell wall to the pathogenesis of experimental otitis media. J Infect Dis. 1988;157(2):245-255.

21. Tuomanen E, Rich R, Zak O. Induction of pulmonary inflammation by components of the pneumococcal cell surface. Am Rev Respir Dis. 1987; 135(4):869-874.

22. Orihuela C, et al. Cell wall-mediated neuronal damage in early sepsis. Infect Immun. 2006;74(7):3783-3789.

23. Cole A, Liao H, Stuchlik O, Tilan J, Pohl J, Ganz $\mathrm{T}$. Cationic polypeptides are required for antibacterial activity of human airway fluid. J Immunol. 2002;169(12):6985-6991.

24. Cramer E, Breton-Gorius J. Ultrastructural localization of lysozyme in human neutrophils by immunogold. J Leukoc Biol. 1987;41(3):242-247.

25. Miyauchi J, Sasadaira H, Watanabe K, Watanabe 
Y. Ultrastructural immunocytochemical localization of lysozyme in human monocytes and macrophages. Cell Tissue Res. 1985;242(2):269-277.

26. Davis K, Weiser J. Modifications to the peptidoglycan backbone help bacteria establish infection. Infect Immun. 2011;79(2):562-570.

27. Vollmer W, Tomasz A. The pgdA gene encodes for a peptidoglycan $\mathrm{N}$-acetylglucosamine deacetylase in Streptococcus pneumoniae. J Biol Chem. 2000; 275(27):20496-20501.

28. Vollmer W, Tomasz A. Peptidoglycan N-acetylglucosamine deacetylase, a putative virulence factor in Streptococcus pneumoniae. Infect Immun. 2002; 70(12):7176-7178.

29. Crisóstomo M, et al. Attenuation of penicillin resistance in a peptidoglycan O-acetyl transferase mutant of Streptococcus pneumoniae. Mol Micro biol. 2006;61(6):1497-1509.

30. Davis K, Akinbi H, Standish A, Weiser J. Resistance to mucosal lysozyme compensates for the fitness deficit of peptidoglycan modifications by Streptococcus pneumoniae. PLoS Pathog. 2008;4(12):e1000241.

31. Serbina N, Jia T, Hohl T, Pamer E. Monocyte-mediated defense against microbial pathogens. Annu Rev Immunol. 2008;26:421-452.

32. Berry A, Yother J, Briles D, Hansman D, Paton J. Reduced virulence of a defined pneumolysin-negative mutant of Streptococcus pneumoniae. Infect Immun. 1989;57(7):2037-2042.

33. Hirst R, Kadioglu A, O'Callaghan C, Andrew P. The role of pneumolysin in pneumococcal pneumonia and meningitis. Clin Exp Immunol. 2004; 138(2):195-201.

34. van der Poll T, Keogh C, Guirao X, Buurman W, Kopf M, Lowry S. Interleukin-6 gene-deficient mice show impaired defense against pneumococcal pneumonia. J Infect Dis. 1997;176(2):439-444.

35. Ueda A, Ishigatsubo Y, Okubo T, Yoshimura T Transcriptional regulation of the human monocyte chemoattractant protein-1 gene. Cooperation of two NF-kappaB sites and NF-kappaB/Rel subunit specificity. J Biol Chem. 1997;272(49):31092-31099.

36. Ratner A, Hippe K, Aguilar J, Bender M, Nelson A, Weiser J. Epithelial cells are sensitive detectors of bacterial pore-forming toxins. J Biol Chem. 2006; 281(18):12994-12998.

37. Gutierrez $\mathrm{O}$, et al. Induction of Nod 2 in myelomonocytic and intestinal epithelial cells via nuclear factor-kB activation. J Biol Chem. 2002; 277(44):41701-41705.

38. Iwasaki A, Medzhitov R. Regulation of adaptive immunity by the innate immune system. Science. 2010;327(5963):291-295.

39. Kobayashi K, et al. Nod2-dependent regulation of innate and adaptive immunity in the intestinal tract. Science. 2005;307(5710):731-734

40. Kobayashi K, et al. RICK/Rip2/CARDIAK mediates signaling for receptors of the innate and adaptive immune systems. Nature. 2002;416(6877):194-199.

41. Magalhaes J, et al. Nod2-dependent Th2 polarization of antigen-specific immunity. J Immunol. 2008; 181(11):7925-7935.
42. Chin A, Dempsey P, Bruhn K, Miller J, Xu Y, Cheng $\mathrm{G}$. Involvement of receptor-interacting protein 2 in innate and adaptive immune responses. Nature. 2002;416(6877):190-194.

43. Divangahi M, et al. NOD2-deficient mice have impaired resistance to Mycobacterium tuberculosis infection through defective innate and adaptive immunity. J Immunol. 2008;181(10):7157-7165.

44. Fritz J, et al. Nod1-mediated innate immune recognition of peptidoglycan contributes to the onset of adaptive immunity. Immunity. 2007;26(4):445-459.

45. Viala J, et al. Nod 1 responds to peptidoglycan delivered by the Helicobacter pylori cag pathogenicity island. Nat Immunol. 2004;5(11):1166-1174.

46. Hruz P, et al. NOD2 contributes to cutaneous defense against Staphylococcus aureus through alpha-toxin-dependent innate immune activation. Proc Natl Acad Sci U S A. 2009;106(31):12873-12878.

47. Geddes K, et al. Nod 1 and Nod 2 regulation of inflammation in the Salmonella colitis model. Infect Immun. 2010;78(12):5107-5115.

48. Kim Y, et al. The Nod2 sensor promotes intestinal pathogen eradication via the chemokine CCL2-dependent recruitment of inflammatory monocytes. Immunity. 2011;34(5):769-780.

49. Burn T, Petrovick M, Hohaus S, Rollins B, Tenen D. Monocyte chemoattractant protein-1 gene is expressed in activated neutrophils and retinoic acid-induced human myeloid cell lines. Blood. 1994; 84(8):2776-2783

50. Yamashiro S, Kamohara H, Yoshimura T. MCP-1 is selectively expressed in the late phase by cytokinestimulated human neutrophils: TNF-alpha plays a role in maximal MCP-1 mRNA expression. J Leukoc Biol. 1999;65(5):671-679.

51. Molofsky A, et al. Cytosolic recognition of flagellin by mouse macrophages restricts Legionella pneumophila infection. J Exp Med. 2006;203(4):1093-1104.

52. Balachandran P, Hollingshead S, Paton J, Briles D. The autolytic enzyme LytA of Streptococcus pneumoniae is not responsible for releasing pneumolysin. J Bacteriol. 2001;183(10):3108-3116.

53. Price K, Camilli A. Pneumolysin localizes to the cell wall of Streptococcus pneumoniae. J Bacteriol. 2009;191(7):2163-2168.

54. Ratner A, Aguilar J, Shchepetov M, Lysenko E, Weiser J. Nod1 mediates cytoplasmic sensing of combinations of extracellular bacteria. Cell Microbiol. 2007;9(5):1343-1351.

55. Howard L, Gooder H. Specificity of the autolysin of Streptococcus (Diplococcus) pneumoniae. J Bacteriol. 1974;117(2):796-804

56 . Boneca I, et al. A critical role for peptidoglycan $\mathrm{N}$-deacetylation in Listeria evasion from the host innate immune system. Proc Natl Acad SciUS A. 2007; 104(3):997-1002

57. Vollmer W. Structural variation in the glycan strands of bacterial peptidoglycan. FEMS Microbiol Rev. 2008;32(2):287-306.

58. Shimada T, et al. Staphylococcus aureus evades lysozyme-based peptidoglycan digestion that links phagocytosis, inflammasome activation, and IL- 1beta secretion. Cell Host Microbe. 2010;7(1):38-49.

59. Girardin S, et al. Peptidoglycan molecular requirements allowing detection by Nod1 and Nod2. J Biol Chem. 2003;278(43):41702-41708

60. Coulombe F, et al. Increased NOD2-mediated recognition of N-glycolyl muramyl dipeptide. J Exp Med. 2009;206(8):1709-1716.

61. Winter C, et al. Lung-specific overexpression of $\mathrm{CC}$ chemokine ligand (CCL) 2 enhances the host defense to Streptococcus pneumoniae infection in mice: role of the CCL2-CCR2 axis. J Immunol. 2007; 178(9):5828-5838.

62. Gordon S, Taylor P. Monocyte and macrophage heterogeneity. Nat Rev Immunol. 2005;5(12):953-964.

63. van Rijt L, Kuipers H, Vos N, Hijdra D, Hoogsteden $\mathrm{H}$, Lambrecht B. A rapid flow cytometric method for determining the cellular composition of bronchoalveolar lavage fluid cells in mouse models of asthma. J Immunol Methods. 2004;288(1-2):111-121.

64. Dunay I, et al. Gr1+ inflammatory monocytes are required for mucosal resistance to the pathogen Toxoplasma gondii. Immunity. 2008;29(2):306-317.

65. Eyerich S, Eyerich K, Cavani A, Schmidt-Weber C. IL-17 and IL-22: siblings, not twins. Trends Immunol. 2010;31(9):354-361.

66. Shoma S, et al. Critical involvement of pneumolysin in production of interleukin-1alpha and caspase-1dependent cytokines in infection with Streptococcus pneumoniae in vitro: a novel function of pneumolysin in caspase- 1 activation. Infect Immun. 2008; 76(4):1547-1557.

67. Littmann M, Albiger B, Frentzen A, Normark S, Henriques-Normark B, Plant L. Streptococcus pneumoniae evades human dendritic cell surveillance by pneumolysin expression. EMBO Mol Med. 2009; 1(4):211-222.

68. Tettelin H, et al. Complete genome sequence of a virulent isolate of Streptococcus pneumoniae. Science. 2001;293(5529):498-506.

69. Markart P, Korfhagen T, Weaver T, Akinbi H. Mouse lysozyme $\mathrm{M}$ is important in pulmonary host defense against Klebsiella pneumoniae infection. Am J Respir Crit Care Med. 2004;169(4):454-458.

70. Faust N, Varas F, Kelly L, Heck S, GrafT. Insertion of enhanced green fluorescent protein into the lysozyme gene creates mice with green fluorescent granulocytes and macrophages. Blood. 2000;96(2):719-726.

71. Bera A, Herbert S, Jakob A, Vollmer W, Götz F. Why are pathogenic staphylococci so lysozyme resistant? The peptidoglycan O-acetyltransferase OatA is the major determinant for lysozyme resistance of Staphylococcus aureus. Mol Microbiol. 2005;55(3):778-787.

72. Kufer TA, Kremmer E, Banks DJ, Philpott DJ. Role for erbin in bacterial activation of Nod2. Infect Immun. 2006;74(6):3115-3124.

73. Lysenko E, et al. Nod1 signaling overcomes resistance of S. pneumoniae to opsonophagocytic killing. PLoS Pathog. 2007;3(8):e118.

74. Miller JH. Assays for $\beta$-galactosidase. In: Miller JH, ed. Experiments In Molecular Genetics. Cold Spring Harbor, New York, USA: Cold Spring Harbor Laboratory; 1972:352-355 